\title{
Using Art In Group Counseling with Native American Youth
}

\author{
Valerie E. Appleton and Cass Dykeman \\ Eastern Washington University
}

This is the author's preprint. The copy of record is the following:

Appleton, V. E., \& Dykeman, C. (1996). Using art in group counseling with

Native American youth. Journal for Specialists in Group Work, 21(4),

224-231. https://doi.org/10.1080/01933929608412254

\begin{abstract}
This article describes a group art counseling program for Native American youth, using art in a group context as the primary counseling intervention in a public school setting. The application of the intervention was found to be consistent with the literature related to counseling with Native Americans and art therapy techniques.
\end{abstract}

Keywords: Native American, youth, group work, counseling, art assisted counseling

\section{Introduction}

Approximately 400,000 children and adolescents live in areas served by Indian Health Services. However, there exists only one health provider per 23,353 Native American youth (U.S. Congress, 1990). Native American youth suffer more serious health and mental health problems than do any other group in the nation (U.S. Congress, 1990). Other startling statistics concerning Native American high school students include, (a) a dropout rate of $60 \%$, (b) an increase of $1,000 \%$ in the adolescent suicide rate over the past 20 years, (c) an arrest rate 10 times that for European Americans and three times that for African Americans, and (d) a drug and alcohol usage rate double the national average (Heinrich, Corbine, \& Thomas, 1990).

The problems cited above are not going to disappear without intervention. Conventional counseling approaches may be inappropriate for Native American communities (Trimble \& Flemming, 1989). Key to the construction of effective counseling interventions with Native American youth is 
the use of culturally relevant therapeutic processes. As representatives of the dominant culture, European American counselors may inadvertently express both overt and covert forms of prejudice and discrimination toward Native Americans (Burt Dtati, 1993; Sue \& Sue, 1990). LaFromboise, Trimble and Mohatt (1990) noted that "Native Americans who do engage in individual counseling often express concern about the shaping of their behavior in a manner that is inconsistent with Indian cultural life-style orientations and preferences" (p. 633). Thus, Native American clients often fear that counselors may try to influence their value system and there by alienate them from their own people and traditions (LaFromboise, et al., 1990).

The traditional Native American healer would rarely treat an individual in isolation (Thomason, 1991). This healer would typically mobilize extended family, friends, and neighbors to both (a) support the individual and (b) integrate him or her into the social life of the group (Lewis \& Ho, 1989). Some tribal groups hold collective discussions where everyone involved with the client would meet and encourage the individual to make a community confession that they are out of harmony with nature (Spector, 1985).

Culturally sensitive counseling approaches with Native American clients incorporate the use of a variety of nonverbal techniques. These techniques include (a) art and play therapy, (b) becoming comfortable with long pauses in conversation, and (c) facilitating group work rather than individual counseling (Lazarus, 1972). Paying close attention to nonverbal communication facilitates the counseling needs of Native American clients (Katz, 1981). Overall, research on counseling Native Americans suggests the need for alternate approaches, because many conventional modalities do not appear helpful to Native American clients (Dykeman, Nelson, \& Appleton, 1995; Herring, 1989, 1990, 1992;

LaFromboise \& Dixon, 1981; Lofgren, 1981; Orlansky \& Trapp, 1987; Trimble, 1981).

Art therapy is considered an appropriate treatment modality for Native American clients by several researchers (Ashby, Gilchrist, \& Miramontez, 1987; Burt Dtati, 1993; Dufrene, 1991; Ferrara, 1991; Lofgren, 1981). Dufrene (1990) suggested that although tribal traditions vary, Native Americans generally view the world holistically where art, beauty, and spirituality are intertwined into the routine of living. Furthermore, Native American aesthetic experiences have survived colonialism, racial discrimination, and rapid technological change. Dufrene (1992) commented that "art is indispensable to ritual, and ritual is the Native American concept of the whole life process. Myths, prayers, songs, chants and sand paintings are used to return the patient symbolically to the source of 
tribal energy. Indian philosophy does not separate healing from art or religion" (p. 3). Art therapy is a form of communication for children that overcomes barriers of culture, income, or life experience (Silver, 1988). Art media provide clients culturally sensitive avenues for expression through nonverbal forms that can inspire, direct, and heal (Gladding, 1992).

The history of delivering counseling services to Native Americans is a history influenced by prejudice and ignorance. As such, Native Americans do not commonly receive counseling services in a form congruent to their worldview. This service failure includes counseling delivered to Native American youth. The purpose of the present article is to help rectify this distressing situation. The following group counseling protocol details a culturally relevant approach designed to assist Native American youth within a school context. The use of art media to facilitate therapeutic processes is the key to this approach. Art in this context creates a symbolic vehicle for creative expression that enhances personal and social functioning (Liebmann, 1991).

\section{Protocol}

The 10 Native American youth used to develop this protocol were of both genders and ranged in age from 7 to 17 . While standard group counseling theory would question such an age range in the composition of a group, this age heterogeneity actually complements Native American cultural patterns. The youth belonged to Nez Pierce, Crow, and Salish speaking tribes and attended a public school located on a Northwest Indian reservation. The school's ethnic composition was roughly $40 \%$ Native American and 60\% European American.

The participants met for 50-minute sessions, once a week, for seven weeks. During each of the seven counseling sessions, students were asked to work on a general theme selected by the counselor and received art materials related to that theme. In a supportive and caring manner, the counselor encouraged the students to develop their own art product (Sue \& Sue, 1990). Presented below is an outline for each session including (a) the session's goal, (b) the related art activity, and (c) the responses from the participants.

\section{Session 1: Introduction}

Goal. The goal of the first session was to form a group through culturally relevant group building experiences. The counselor had each group member introduce themselves through a family drawing in order to initiate the process of group formation. This self-introduction in relationship to family is the norm 
among Native American people. Also, the family drawing is useful for the projection of: (a) intimacy or distance, (b) emotional tone in the family, (c) pleasantness or unpleasantness in the home setting, and (d) feelings of who is closest to whom (Wohl \& Kaufman, 1985).

Art Activity. The counselor handed out newsprint $(46 \mathrm{~cm}$ by $61 \mathrm{~cm}$ ) and soft chalk pastels. The chalk pastels should include at least 12 colors to allow a wide range of affective expression. To begin the family drawing, the counselor gave the directive, "Draw yourself and your family." More specific directives should be avoided because they may limit autogenic expression.

After the family drawing project, the students developed the group rules with the help of the counselor. The participants agreed to the following rules: (a) everything said in the group stays in the room, (b) only "nice" things are said in the group, (c) people in the group do not have to talk if they do not want to, (d) only one person can talk at a time, and (e) students must be on time to the group.

Responses. In their drawings, the Native American students included many more family members than is typical of the European American students. Of the Native American youth that participated in the protocol development, 8 out of 10 included grandparents or significant aunts and uncles in their family drawings. This finding reflects that among the Native American youth, extended family members live in the home and are essential in the definition of family. Another characteristic found in the participants' drawings was that 6 of the 10 listed the mother as the head of the family, even if the father was present in the home. The intimate sharing facilitated through the family drawing experience formed the foundation of the group's cohesion.

\section{Session 2: Home and Family}

Goal. The goal of this session was to explore the students' feelings of security and safety within the home. The art activity chosen used to meet this goal was the drawing of a house. This drawing provided a way to measure the student's feelings concerning their basic family needs. Specifically, needs related to security and affection (DiLeo, 1983). House drawings often contain symbolic representations of maturity, adjustment, accessibility to others, contact with reality, and general emotional stability (Buck, 1981).

Art Activity. To provide a bridge from the first session, the same media (newsprint and chalk) were used. The counselor again gave only a simple 
command, "Draw a picture of a house." When given such an open-ended directive, students will often ask "Should I draw my own house?" The counselor should assure the students that drawing any house is allowed. Any further directives from the counselor can pollute the therapeutic art process.

Responses. All Native American students in the group expressed concerns about their safety and security. Two older Native American students stated that they wished they were not living at home. Compared to the European American students we have worked with, the Native American students produced more options when asked where they would go if they lost their homes. This ability to produce more options results from the specific worldview of Native Americans (LaFromboise et al., 1990; Sodowsky \& Johnson, 1994). One Native American student said his tribe would take care of him and others discussed living with relatives in different locations.

In this session, older students (aged 14 to 17) expressed apprehension about using the material, with statements such as, "I don't know how to paint," or "I'm no good at this." The younger students (aged 7 to 13) were relaxed and open to the exploration of the media. All group members were encouraged and supported by the counselor in their use of art media. The resistance encountered in the older students is typical of this age group when using media. This resistance is best overcome through a counselor's use of an empathic and nonjudgmental response style.

\section{Session 3: "Building Out"}

Goal. The goal of this session was the promotion of self-knowledge. This session used collage as a symbolic door to self-understanding. According to Robbins and Sibley (1976), this is a "building out" activity that helps the individual picture his or her role in the world. Collage provides a safe way for the students to integrate self and environment because it gives the right amount of both structure (i.e., sorting pre-made images) and freedom (i.e., building collages).

Art Activity. The counselor had the students thumb quickly through popular magazines for images. The accent on speed prevents making this process too cognitive. Consistent with the speed imperative, the students were instructed to rip rather than cut the selected images out of the magazines. Once stacks of images were collected, the counselor gave the students white glue and newsprint. Then, the students were told to cull through their images and construct collages. 
The specific directive for this art experience was, "Make a picture about you in your world."

Responses. The students were very selective about what images to use in their collage and reported them as very personal. Two Native American students did not like the selection of magazines that included National Geographic, Country Living, Photography, and Sports Illustrated. They stated that they found nothing in the magazines that represented who they were, so they recombined images in way that reflected their sense of cultural identity. The Native American high school students used images that projected strength, power, and nature.

\section{Session 4: Affective Themes}

Goal. The goal of this session was to encourage affective expression through spontaneous drawing. This activity allowed the students to deal with the expression of unconscious factors that effect perceptions, judgments, and behaviors (Robbins \& Sibley, 1976). Art Activity. During this session the counselor encouraged students to become aware of their feelings about what they like and dislike most. Students drew on newsprint with colored felt pens. The specific instruction given by the counselor was, "On one side of the paper, draw things you like; on the other side draw things that you do not like."

Responses. The main themes that emerged among the participants were anger and resentment. The Native American students drew pictures of European Americans on the "Dislike" side. The depiction of European American persons as disliked objects is consistent with the Immersion stage of racial identity formation in students of color (Helms, 1994). One Native American student drew a picture of a western soldier. He explained that the soldiers took their land away from them and it is the White man's fault that he had to live on this reservation. The art experiences helped these students to (a) contact, (b) express, and (c) work through the anger inherent in the Immersion stage. It is only by this working-through that students of color can move onto the Integration stage where both racial self-esteem and multicultural dialogue are possible (Helms, 1994).

\section{Session 5: Cognitive Themes}

Goal. The goal of this session was to allow students to thematicize the affective experiences encountered in Session 4. Thematicizing these experiences provided a therapeutic container for the deep affective work evoked in the 
previous session. The specific cognitive theme was the meaning of "image" to the individual students.

Art Activity. Each participant again received newsprint and colored felt markers. The counselor instructed the students to, "With your eyes closed, scribble for 30 seconds." After the 30 seconds, the counselor stated, "Now find a shape, image, or symbol within the scribble and make it look more like what you see." This activity allows individuals an opportunity to think through their own self-discovery processes (Robbins \& Sibley, 1976).

Responses. One Native American student developed a picture of an eagle from the scribbles and another developed a horse. Most of the other students' pictures were of various imaginary people, animals, or bugs. When asked to discuss their drawings, the younger Native American students were quite creative and included comments such as, "It's an alien from outer space," and "It is a creature that lives in the mountains by my house." No common themes emerged from their drawings.

\section{Session 6: Return to the Affective Themes}

Goal. This session returned to the affective themes begun in Session 4 and thematicized in Session 5. Consequently, a clay media was selected. Both the process and product of clay work provided students opportunities for expression and mastery of affective themes.

Art Activity. The counselor gave each student a chunk of water-based clay. The counselor's specific directive to the students was, "Create something you have imagined or dreamed." After creating the clay product, the counselor asked the students to describe: (a) the process of working with clay, (b) the clay product, and (c) the feelings associated with their creations. During any discussion of art products, the counselor should monitor the group process to insure that all feelings and art work are respected by group members.

Responses. The clay products contained themes of powerlessness. For example, a number of students constructed monster images. One student, responding to his own fear elicited by the art process, ridiculed others who had voiced their fears. The counselor had to intervene at this point in the process in order to maintain the integrity of the group. Overall, counselors should be prepared for the possibility that art processes will elicit strong feelings. 


\section{Session 7: Closure}

Goal. The goal of this session was twofold. First, to bring closure to the group process by honoring the gifts brought to the group by each of its members. Second, to consider how the new found knowledge and relationships supplied by the group might be used.

Art Activity. The termination exercise was a whole-body tracing on paper. Felt markers were used to trace around each individual group member. Specifically, the counselor directed the students to work in pairs and trace each other's body. Also, the counselor asked each student being traced to, "Say something about your experience in our group." This technique is intended to build trust as well as allow students to bridge between feeling, thinking, revealing, and doing (Robbins \& Sibley, 1976).

Responses. The high school students' comments were very positive, "I wish it would last for the rest of the school year," "I liked it, it got me out of class," or "It was fun, I learned a lot about the others and myself in the group." The younger students had similar comments about the group art experience. However, they expressed stronger positive feelings about the art activities than did the older students.

\section{Conclusion}

Native Americans often view the world in a more holistic manner than do European Americans (Heinrich, Corbine, \& Thomas, 1990). This holistic view of life includes regarding art as an essential and inseparable element of life (Dufrene, 1992). The counseling protocol outlined above details how to use art with group counseling for Native American students. Culturally congruent art processes will help these students to explore their identity in relation to family, tribe, and nonNative society. In particular, the power of art processes can elicit strong feelings about the marginalization of Native Americans. Any counselor employing this protocol must be prepared to deal with strong emotions such as anger, loss, and despair. A number of resources exist for counselors considering the use of artbased interventions. Liebmann's (1991) text on art work with groups is an excellent starting point. Also, registered art therapists (ATR) can serve as valuable consultation resources for more in-depth questions.

Another benefit of this group approach is that it provides Native American students a sense of safety within a potentially threatening European American dominant system--the public school system. It is only within a safe context that Native American students can accomplish the healing and growth 
requisite to entering cross-cultural dialogues. Thus, group counseling experiences with art can be a vehicle for greater societal reconciliation around issues of race.

\section{References}

Ashby, M. R., Gilchrist, L. D., \& Miramontez, A. (1987). Group treatment for sexually abused American Indian adolescents. Social Work with Groups, 10, 21-31.

Burt Dtati, H. (1993). Issues in art therapy with culturally displaced American Indian youth. Arts in Psychotherapy, 20, 143-151.

Buck, J. (1981). The house-tree-person technique. Los Angeles, CA: Western Psychological Services.

DiLeo, J. H. (1983). Interpreting children's drawings. New York: Brunner/Mazell.

Dufrene, P. (1990). Exploring Native American symbols. Workshop presented 30th National Art Education Association. (ERIC Document Reproduction Service No. ED 334 124).

Dufrene, P. (1991). Utilizing the arts for healing from a Native American perspective: Implications for creative arts therapists. Brandon University, Department of Native Studies, Manitoba, Canada. (ERIC Document Reproduction No. ED 334 125).

Dufrene, P. (1992). Utilizing the arts for healing from a Native American prospective: Implications for creative art therapies. (ERIC Document Reproduction Service No. ED 334 125).

Dykeman, C., Nelson, J. R., \& Appleton, V. (1995). Building strong working alliances with American Indian families. Social Work in Education, 17, 148-158.

Ferrara, N. (1991). Luke's map of the journey: Art therapy with a Cree Indian Boy. Journal of Child and Youth Care, 6, 73-78.

Gladding, S. T. (1992). The expressive arts in counseling. (ERIC Document Reproduction Service No. ED 350 528).

Heinrich, R. K., Corbine, J. L., \& Thomas, K. R. (1990). Counseling Native Americans. Journal of Counseling and Development, 69, 128-132.

Helms, J. (1994). Racial identity in the school environment. In P. Pedersen \& J. C. Carey (Eds.), Multicultural counseling in schools (pp. 19-38). Needham Heights: MA: Allyn \& Bacon.

Herring, R. D. (1989). Counseling Native American children: Implications for elementary school counselors. School Guidance and Counseling, 23, 272281.

Herring, R. D. (1990). Understanding Native American values: Process and content for counselors. Counseling and Values, 34, 134-137. 
Herring, R. D. (1992). Seeking a new paradigm: Counseling Native Americans. Journal of Multicultural Counseling and Development, 20, 35-43.

Katz, P. (1981). Psychotherapy with Native adolescents. Canadian Journal of Psychiatry, 26, 455-459.

LaFromboise, T. D., \& Dixon, D. N. (1981). American Indian perception of trustworthiness in a counseling interview. Journal of Counseling Psychology, 28, p.135-139.

LaFromboise, T. D., Trimble, J. E., \& Mohatt, G. V. (1990). Counseling intervention and American Indian tradition: An integrative approach. Counseling Psychologist, 18, 628-654.

Lazarus, A. (1972). Clinical behavior therapy. New York: Brunner/Mazel.

Lewis, R., \& Ho, M. (1989). Social work with Native Americans. In D. Atkinson, G. Morten, \& D. Sue (Eds.), Counseling American minorities. Dubuque, IA: William C. Brown.

Liebmann, M. (1991). Art therapy for groups: A handbook of themes, games and exercises. Cambridge, MA: Brookline Books.

Lofgren, D. E. (1981). Art therapy and cultural difference. American Journal of Art Therapy, 21, 25-30.

Orlansky, M. D., \& Trapp, J. J. (1987). Working with Native American persons: Issues in facilitating communication and providing culturally relevant services. Journal of Visual Impairment and Blindness, 81, 151-155.

Robbins, A., \& Sibley, L. B. (1976). Creative art therapy. New York: Brunner/Mazel.

Silver, R. (1988). Screening children and adolescence for depression through draw-a-story. American Journal of Art Therapy, 26, 19-124.

Sodowsky, G. R., \& Johnson, P. (1994). World views: Culturally learned assumptions and values. In P. Pedersen \& J. C. Carey (Eds.), Multicultural counseling in schools (pp. 59-80). Needham Heights: MA: Allyn \& Bacon.

Spector, R. (1985). Cultural diversity in health and illness. Norwalk, CT: Appleton Century Crofts.

Sue, D. W., \& Sue, D. (1990). Counseling the culturally different: Theory and practice. New York: Wiley

Thomason, T. C. (1991). Counseling Native Americans: An introduction for non-Native American counselors. Journal of Counseling and Development, 69, 321-326.

Trimble, J. E., (1981). Value differentials and their importance in counseling American Indians. In P. Pedersen, J. E. Draguns, W. J. Lonner, \& J. E. Trimble (Eds.), Counseling across cultures. Honolulu: University of Hawaii Press. 
Trimble, J. E., \& Flemming, C. M. (1989). Providing counseling services for Native American Indians: Clients, counselor, and community characteristics. In P. B. Pedersen, J. E. Draguns, W. J. Lonner, \& J. E. Trimble (Eds.), Counseling across cultures. Honolulu: University Press of Hawaii.

U.S. Congress, Office of Technology Assessment. (1990). Indian adolescent mental health (OTA Publication No. H-446). Washington, DC: U.S. Government Printing Office.

Wohl, A., \& Kaufman, B. (1985). Silent screams and hidden cries. New York: Brunner/Mazel. 